\title{
TETANUS - AN EVALUATION OF EPIDEMIOLOGIC DATA IN BRAZIL
}

\author{
Paula do Patrocínio Dias ${ }^{\circ}$ \\ Suzana Ramos Ferrer ${ }^{b}$ \\ Hygia Maria Nunes Guerreiro ${ }^{c}$
}

\begin{abstract}
Tetanus is an infectious preventable disease caused by Clostridium tetani that still occurs in large numbers in Brazil and has high mortality rates. Epidemiological data on morbidity and mortality of accidental and neonatal tetanus in Brazil from 2008 to 2011 were collected from the System of Information of Notifiable Diseases available on line. There were 1299 cases of accidental tetanus cases with 419 (32\%) deaths. Men aged 20 to 59 years were most affected. High numbers of accidental tetanus are probably related to more exposure to risk factors. The lack of special campaigns for tetanus revaccinations every ten years is another important factor. The fewer number of cases of neonatal tetanus (23) is related to the success of governmental vaccination program targeted to this age group. Despite low numbers, death rate is high, $65 \%$ among neonatal cases.
\end{abstract}

Keywords: Tetanus. Epidemiology. Brazil.

\section{INTRODUCTION}

Tetanus, a severe disease characterized by trismus, fever, episthotonus and difficult swallowing, is caused by the obligate anaerobic Gram positive bacillus Clostridium tetani found in worldwide soils. $(1,2)$ Severe cases can lead to death. Notification of tetanus cases started in 1982 in Brazil. The program for neonatal tetanus eradication started in 1992 ensuring children and mothers vaccination. Since then there has been a significant decrease in incidence among neonates. Accidental tetanus nonetheless still has a high number of cases, due to the fact that most adults don't come back to revaccination every ten years as recommended. The goal of this study is to analyze the epidemiological data of tetanus in Brazil from 2008 to 2011, in order to increase awareness of tetanus cases still occurring after almost ten years of the neonatal eradication programs.

Corresponding author: pauladpdias@gmail.com

a. Biomedical student from Bahiana School of Medicine and Public Health, Salvador, Bahia, Brazil

b. Assistant Professor of Biomedicine, Bahiana School of Medicine and Public Health, Salvador, Bahia, Brazil.

c. PhD, Adjunct Professor of Biomedicine, Bahiana School of Medicine and Public Health, Salvador, Bahia, Brazil 


\section{MATERIAL AND METHODS}

The data on morbidity and mortality of accidental and neonatal tetanus were collected from the on line System of Information of Notifiable Diseases SINAN (Sistema de Informação de Agravos de Notificação). ${ }^{(3)}$ The data about tetravalent coverage were collected at the System of Information of the National Program of Imminuzations (Sistema de Informação do Programa Nacional de Imunizações - SI-PNI). ${ }^{(4)}$ Morbidity data of accidental tetanus, from 2008 to 2011 , were analyzed and processed according to age, sex, education, federal unit notification and evolution to death. Morbidity data of neonatal tetanus from the same period were analyzed and processed according to the federal unit notification, mother's education, mother's age and evolution to death. Tetravalent coverage data from
2008 to 2011 were processed according to the federal unit notification. Tetravalent coverage was chosen because DTP vaccine was replaced by tetravalent vaccine as from 2003.

Microsoft Excell software was used to collect and analyze data.

\section{RESULTS}

There were 1299 cases of accidental tetanus in Brazil from 2008 to 2011 , with a lethality rate of $32,2 \%$. Males individuals aged between 20 and 59 were the most affected group (Figure 1).

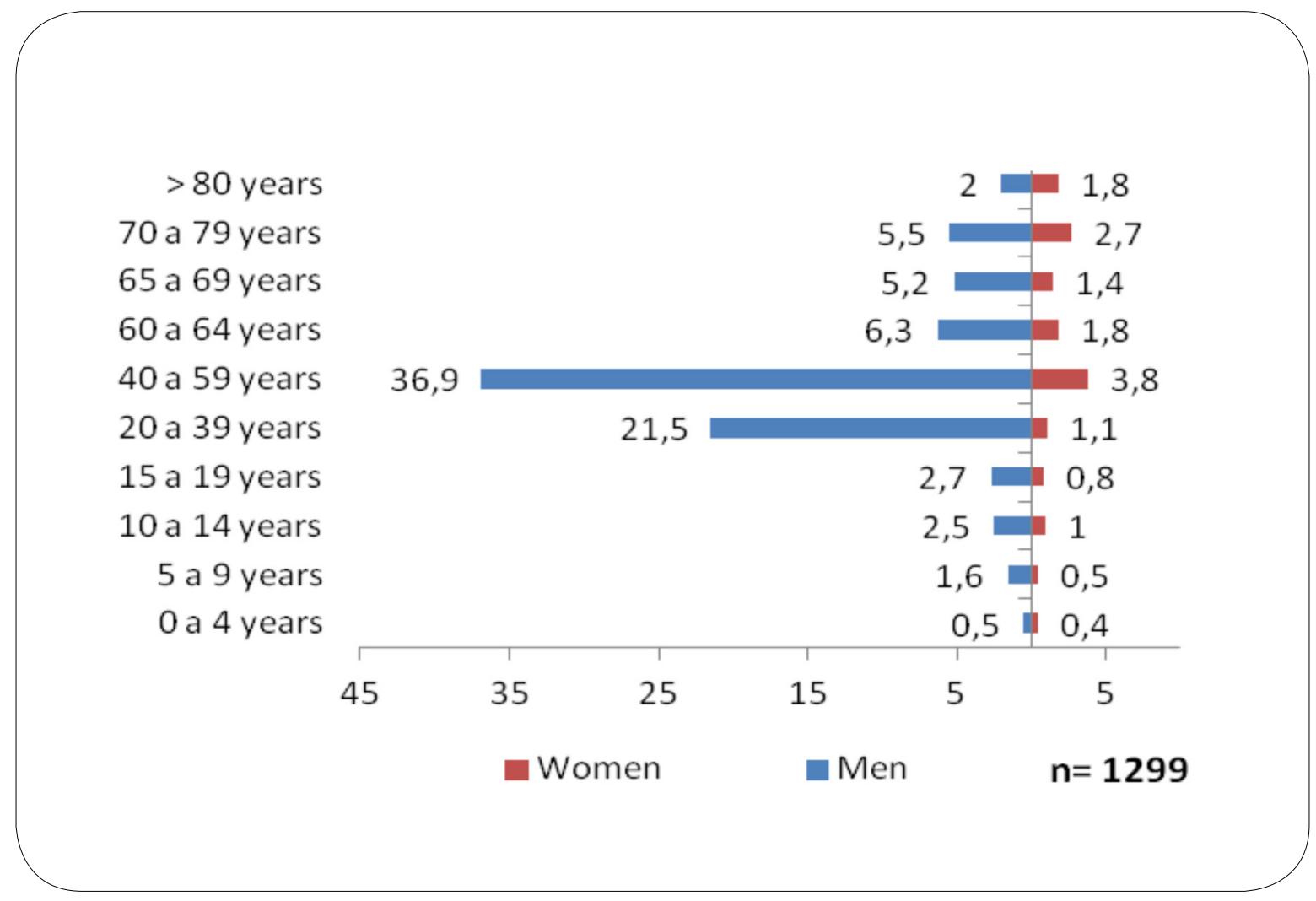

Figure 1. Distribution of Accidental Tetanus Cases by Age and Sex in Brazil, 2008 to 2011.

Regional distribution is shown on Table 1: the majority of accidental cases (77.3\%) occurred in the northeast region, followed by southeast and south of Brazil. Death rate was also higher in the Northeast region (29.8\%). Furthermore, $87 \%$ of neonatal tetanus were from North and Northeast regions, with a lethality of $56.5 \%$. 
Table 1. Cases of Accidental and Neonatal Tetanus in Brazil Regions from 2008 to 2011

\begin{tabular}{|c|c|c|c|c|c|c|c|c|}
\hline \multirow{3}{*}{$\begin{array}{c}\text { COUNTRY } \\
\text { REGION }\end{array}$} & \multicolumn{4}{|c|}{ ACCIDENTAL TETANUS } & \multicolumn{4}{|c|}{ NeOnatal Tetanus } \\
\hline & \multicolumn{2}{|c|}{$\begin{array}{c}\text { CONFIRMED } \\
\text { CASES }\end{array}$} & \multicolumn{2}{|c|}{$\begin{array}{c}\text { EVOLUTION TO } \\
\text { DEATH }\end{array}$} & \multicolumn{2}{|c|}{$\begin{array}{c}\text { CONFIRMED } \\
\text { CASES }\end{array}$} & \multicolumn{2}{|c|}{$\begin{array}{c}\text { EvOLUTION TO } \\
\text { DEATH }\end{array}$} \\
\hline & $\mathrm{N}^{\circ}$ & $\%$ & $\mathrm{~N}^{\circ}$ & $\%$ & $\mathrm{~N}^{\circ}$ & $\%$ & $\mathrm{~N}^{\circ}$ & $\%$ \\
\hline NORTH & 148 & 11.4 & 52 & 13.2 & 10 & 43.5 & 6 & 26.1 \\
\hline NORTHEAST & 486 & 37.4 & 138 & 29.8 & 10 & 43.5 & 7 & 30.4 \\
\hline MIDWEST & 147 & 11.3 & 41 & 10.7 & 1 & 4.3 & 1 & 4.3 \\
\hline SOUTHEAST & 260 & 20.0 & 88 & 20.7 & 1 & 4.4 & 1 & 4.4 \\
\hline SOUTH & 258 & 19.9 & 100 & 25.6 & 1 & 4.3 & 0 & O \\
\hline TOTAL & 1299 & 100 & 419 & 32.2 & 23 & 100 & 15 & 65.2 \\
\hline
\end{tabular}

Source: Brasil, 2012.

The analysis of the cases of accidental tetanus and education level in this study population shows that $5.9 \%$ were analphabets, $21.8 \%$ had between one to five years of education, $22.7 \%$ had between six and twelve years of education. This information is not applicable in $1.3 \%$. There was no information for almost half of the population studied: $47.4 \%$.

In $65.2 \%$ of the neonatal cases, the mothers of the affected children had no more than five years of education or no school education at all, $21.7 \%$ of them had between six and twelve years of education, $4.3 \%$ had college education and for $8.8 \%$ education data was not reported. Mother's age was also analyzed: $26.1 \%$ were more than 30 years old, $47.8 \%$ were aged between 20 and 29 years, $17.4 \%$ between 15 and 19 years and $8.7 \%$ had no age information reported.

\section{DISCUSSION}

Tetanus has been notifiable in Brazil since 1982. A program for eradication of neonatal cases started 1992 and since then, neonatal tetanus has been drastically reduced. Vaccination coverage programs aimed to mothers and children was spread to all regions, even in places difficult to access, where transport is a great issue. ${ }^{(5)}$

The greater incidence of accidental tetanus in men aged 20 to 59, is compatible to previous data in Brazil.
Men were five times more affected than women, what is in accordance to other studies. ${ }^{(6)}$ Explanation to this fact is related to two main aspects: one is that men are more exposed due to their professions. Many tetanus cases occurs in those working with soil such as agricultures, gardeners and bricklayers. The other aspect is that prevention in adults depends on revaccination every ten years; this is not a well known fact for the lay population.

There is a relation of low grade education and tetanus cases, $27.7 \%$ of accidental cases had five or less years of schooling and in $65.2 \%$ of the neonatal cases, the mothers of the affected children had no more than five years of education or no education at all. (7) The incidence of neonatal tetanus is directly related to poverty, low education and age of the mother, as well as difficulty in accessing health and prenatal services and inadequate vaccination. ${ }^{(8)}$

Better socioeconomic conditions are directly related to more frequently access to health services and awareness of the need for vaccination, so the low education is one of the socioeconomic factors that influence the prevention of tetanus 6 . The incidence of tetanus is related to a number of factors such as: vaccination interruption, and, therefore inadequate vaccination, exposure to the risk factors, and especially the lack of knowledge about the disease

Brazil is a large country with an territory of $8.515 .767,049 \mathrm{~km}^{2}$, with huge differences in relation 
to socio-economical conditions. Our data show a difference in Brazil regions where Northeast, an underprivileged region, has a higher concentration of accidental tetanus as well as death. On other hand, South and Southeast are more developed regions, and in this case the high numbers of accidental tetanus can be explained by the fact that their main economic activity is agricultural.

Our main conclusion is the need of special public health prevention program for accidental tetanus. Adult male population should be a special target. The program should make available information on different forms of contamination. Individuals should be instructed to seek help in the case of injuries to receive adequate prophylaxis.

It is important to notice that investment in education by the Brazilian government would certainly reduce the number of cases the disease, since the data findings suggest a relationship between low education and incidence of tetanus, both for accidental and neonatal cases. It is also necessary provide guidance for mothers during the prenatal period about the importance of vaccines and basic hygiene of newborns, with special focusing on the cleaning and proper management of the umbilical stump, usual gateway for contamination by $\mathrm{C}$. tetani in neonates.

The proper notification of notifiable diseases is essential for the completion of data that really reflect the reality found on health units. It would be important to have more information about the professional activities more frequently related to each tetanus case in different regions of Brazil, aiming that a more precise preventive project may be proposed.

\section{References}

1. Gomes AP. et al. Infecção por Clostridium tetani no recém-nascido: revisão sobre o tétano neonatorum. Rev. bras. ter. intensiva, 2011; 23(4):484-491.

2. Roper MH, Vandelaer JH, Gasse FL. Maternal and neonatal tetanus. Lancet, 2007; 37O(9603):19471959.

3. Brasil. Ministério da Saúde. Sistema de Informação de Agravos de Notificação. Tétano Neonatal: período de 2008 a 2011. Brasília, 2010. [Citado 07 jul 2012]. Disponível em: http://dtr2004. saude.gov.br/sinanweb/

4. Brasil. Ministério da Saúde. Sistema de Informação de Agravos de Notificação. Tétano acidental: período de 2008 a 2011. Brasília, 2010. [Citado O7 jul 2012]. Disponível em: http://dtr2OO4. saude.gov.br/sinanweb/

5. Brasil. Ministério da Saúde. Programa Nacional de Imunizações 30 Anos. 2003. [Citado 14 jun 2013]. Disponível em: https://docs.google.com/ viewer?url=http\%3A\%2F\%2Fbvsms.saude.gov. br\%2Fbvs\%2 Fpoliticas\%2Flivro_3O_anos_pni.pdf

6. Alvis $\mathrm{N}$ et al. Impacto epidemiológico y económico de la vacunación contra el tétanos en adultos de Colombia. Rev. panam. salud publica, 2O11; 30(3):09-216.

7. Feijão $A R$ et al. Tétano acidental no estado do Ceará, entre 2002 e 2005. Rev. Soc. Bras. Med. Trop. 2007; 4O(4):426-430.

8. Nankabirwa V. et al. Maternal education is associated with vaccination status of infants less than 6 months in Eastern Uganda: a cohort study. BMC Pediatr. 2010 [cited 17 Oct. 2012]; 92(10). Available from: http://www.biomedcentral.com/14712431/10/92

9. Instituto Nacional de Geografia Estatística. Área territorial brasileira. 2010. [citado 14 jun 2013]. Available from: http://www.ibge.gov.br/home/ geociencias/cartografia/default_territ_area.shtm 